\title{
WORKING IN SHIFTS AND THE METABOLIC SYNDROME: EPIDEMIOLOGICAL EVIDENGE AND PHYSIOPATHOLOGICAL MECHANISMS
}

\section{Oțelea Marina Ruxandra1, Rașcu Agripina1, Ion lleana², Arghir Ioan Anton.', Badiu Adela3, Ciobotaru Camelia², Rascu Alexandra -Maria', Arghir Oana Gristina²}

${ }^{1}$ University of Medicine and Pharmacy "Carol Davila", Bucharest, Romania

${ }^{2}$ Faculty of Medicine, University "Ovidius" of Constanta, Romania

${ }^{3}$ County Clinical Emergency Hospital of Constanta "St. Andrew", Constanta, Romania

\section{ABSTRACT}

The Metabolic syndrome (MetS) is considered as an association of the abdominal obesity, abnormal metabolism of the lipids and glucose (high level of triglycerides, low level of HDL-cholesterol and high level of glycemia) and high values of blood pressure, determined by an underlying mechanism of insulin resistance. As a result of environmental- gene interaction, MetS is associated with unhealthy nutrition, smoking, alcohol abuse, lack of physical activity, shorter sleep duration and desynchronization of the circadian rhytm caused by working in shifts. The aim of this article is to review the effects of working in shifts on the MetS through the epidemiological evidence and the perspective of the physiopathological mechanisms.

Keywords : working in shifts, metabolic syndrome

\section{Introduction}

Metabolic syndrome (MetS) has a pathogenesis which is not sufficiently known, still on debate. Most authors considered MetS related to "atherogenic dyslipidemia, abdominal obesity, increased values of blood pressure, insulin resistance \pm glucose intolerance, proinflammatory and prothrombotic states" (1). Shift work is associated with several risk factors, influenced by lifestyle, as drinking cofee and/ or alcohol, smoking, aging and obesity, having adverse effects on the architecture of sleep, sleep maintenance, mental, cardiovascular and metabolic disorders and diseases, with unclear relationships (2). Night shift workers have tendency to a lower socio-economic status (3), a higher total calorie intake, a shorter sleep duration (4) and irregular sleeping hours, and more of them are smokers (3-5). For these reasons, shift working was proposed an occupational hazard for the pathogenesis of MetS.

\section{Epidemiological data}

The epidemiological studies in the area of shift working, as a risk factor for MetS, have explored either the relation with the components of MetS or with the MetS' major consequences (diabetes, cardio-vascular diseases). 
Obesity. A systematic review, published several years ago, in 2011, found strong evidence for a crude association between obesity and nightshift (6) and other supplementary data, published later, confirmed and sustained the association $(4,7,8)$. A quantitative relation was established between the obesity and the intensity of long term exposure, estimated by the number of years of night shift or number of nights shifts per week. A recent meta-analysis on obesity, based on 28 performed studies, estimated an overall odds ratio (OR) for obesity (1.23) and abdominal obesity (1.35) in night shift workers, revealing a higher risk in the permanent night workers (1.43) versus the rotating shift workers (1.14) (10).

The lipid profile. Several studies involving workers in shifts showed higher levels of triglycerides and LDL cholesterol, with lower values of HDL cholesterol $(11,12)$. Among a large cohort of 27,485 individuals, a Swedish study, identified a cluster of MetS components (obesity, high triglycerides, and low HDL cholesterol) to be rather characteristic for shift workers (13). Some other researchers did not confirm the relation between MetS and shift work, or the significance of the association decreased when poor sleep quality, age adjustments and lifestyle factors were also included in the analysis $(14,15)$.

Diabetes. A longitudinal study, with a 9.9 years follow-up time of surveillance, noticed counterclock nightshift work determined higher levels of $\mathrm{HbAlc}$, influenced by the scheduling scheme of the working cycle (16). Two large cohort studies confirmed that long duration or more frequent exposure were associated with an increased prevalence of diabetes. One study conducted, in Sweden, by Karlsson et al, in pulp and paper manufacturing plants, found a liniar relation between the number of shift years of exposure and mortality (17). The Healthy Nurse Study, performed in the United States, investigated the risk factors for major chronic diseases, among women, and revealed a threshold of $\geq 3$ night shifts per month as a risk factor for type 2 of diabetes (18). Consistent with these results, it was reported the difficulty in controling the lower levels of HbA1c among nightshift workers with diabetes (19).

Cardiovascular disease. A high risk of cardiovascular diseases was reported in different worldwide populations living in Europe $(20,21)$, North and South America (22) or Asia (23). Night working is associated with an increased carotid-intima-media thickness (24), considered a reliable marker of the atherosclerosis process. The longer exposure to nightshift working is, a higher risk of cardiovascular outcomes has to be estimated (25). However, some studies assessed the presence of the cardiovascular risk factors without a significant raised blood pressure (either systolic, or dyastolic value) (20). One meta analysis, restricted to the cohort studies in rotating shifts, calculated a pooled OR of 1.34 for hypertension, whereas in cross sectional studies, the OR was significantly lower $(\mathrm{OR}=1.07)(26)$. These different conclusions of epidemiological studies could be related to several factors, as the type of rotating shift (day shifts, or day and shifts, clockwise, counterclokwise, weekly nightshift, 8 hours work/12 hours free time etc). For example, the analysis of 54,724 women, included in the The Nurses' Health Study (4), had underlined stronger association among the night shift nurses compared to the rotating shifts ones, who were more influenced by aging. Another factor, which interferes the results, is the follow- up length of time. Some components of the MetS (obesity and abnormal lipid profile) seem to be influenced by different exposure time, even shorter one (27). Follow up surveillance time could be biased by the effect of healthy worker, that underestimated the risk of cardiovascular disease. In occupational cohort studies, the "healthy worker effect" is referring to the fact that employees that get some targeted disease can lose the job, for medical grounds, and are no more identified as cases during the follow up period. Concerning different cohorts of nurses, the turnover in employement is variable, and, sometimes, influenced by the presence of a chronic disease $(28,29)$. In fact, one of the main reasons nurses are changing their job is the schedule of time (30), reflecting also the role of personal cronotype. An evening cronotype increased the risk, while the early morning cronotype has no influence (31). The relation between chronotype and diabetes risk was present in the analysis of the participants in Nurses' Health Study, absent in the UK Biobank 
study analysis (32), quite inconclusive. Workers in the early chronotype class presented the most changes concerning the metabolic profiles (33).

Race might determine some discrepencies because the prevalence of obesity and the abdominal adiposity, or the risk of raised blood pressure are different according to genetic factors. In the UK Biobank study, authors assessed the relationship between shift work exposure and diabetes, revealing significantly higher odds ratio $(\mathrm{OR}=1.44)$, particularly in rotating shift workers, but no interaction was determined between the genetic risk for type 2 diabetes and the current work schedule, the number of years with night shift schedule, or the average lifetime night shift frequency (32). Based on these large prospective epidemiological studies, working in shifts can be considered as a relevant risk factor for the occurrence of MetS.

\section{Physiopathological mechanims}

3 to $10 \%$ of the gene transcripts have, rhythmically, a 24 hour- cycle (34). Day peak transcripts have been described for some proteins (e.g. proteins involved in inflammation and hormonal response, including insulin) (35), while others have a night peak (e.g. proteins involved in ribosomal and epigenetic processes such as the methyltransferases)(36). Theintrinsecoscillations of the brain and muscle ANRT-like protein-1 (BMAL1) and circadian locomotor output cycles kaput (CLOCK) are the substrate of the circadian cycle, located in the suprachiasmatic nucleus. The nuclear translocation of the heterodimer, formed by CLOCK and BMAL1, initiates the transcription of PER2-CRYs and REV-ERBs genes that provide the feedback control of the circadian rhythm, but also of numerous other proteins and hormons that regulate metabolism, such as glucocorticoid, insulin, leptin, ghrelin, vasopressin etc. Light, primarly via melatonin level regulation, effort and nutrition are the best characterized environmental factors to influence the spontaneous oscillations of the central clock. The central clock provides input for the peripheral expression of the clock genes. The majority of the cells of the human body have "a clock gene expression". Fundamental research has identified several functions of the clock genes related to peripheral metabolism regulation; for example, CLOCK-BMAL1 influences the transcription of genes involved in the lipid metabolism, PER2-CRY influences the transcription of genes participating to the cell stress reaction, glucose (e.g. repression of the glucoso-6-phosphatase transcription) and lipid metabolism (competitive activity with PPAR $\alpha$, a ligand for the transcription of the genes that activate the fatty acids oxidation) and the cell cycle (37), including the adipogenesis (38). At cellular level, the oxidative status, reflected in NAD+/NADH balance, is also influenced by the clock genes. Loss of BMAL1 activity in liver, for example, causes swollen of mithocondria, and affects the mithocondrial oxidative phosphorylation (39). The influence is reciprocal, as, NAD + dependent sirtuin 1 activity generates a negative feedback loop to the central clock genes. Another intersection, at cellular level, is between the clock genes and the AMPactivated protein kinase (AMPK) level. AMPK is a regulator of the CRY and PER proteins levels (39). CLOCK and BMAL1 induce the transcription of the ATP-synthetase expression (40). In pancreatic cells, these clock genes reduce the uncoupling protein 2 (41). It is important to notice that increased levels of uncoupling protein 2 have been found in patients with diabetes, associated with a reduction in the ATP content of the $\beta$-cells and blunted insulin secretion (42).

Beside these metabolism regulators, metabolomic studies sustained that around 15\% of the low molecular weight metabolites have circadian variations (43) and lipidomics have also shown a circadian variation in $13.3 \%$ of plasma lipids (44). The circadian oscillation of the clock genes is considered an adaptive mechanism to restricted feeding and to the preservation of energy. In the context of no restricted food availability, the adaptive mechanism lost its initial relevance. Meantime, as the external disruptors of this mechanism are more and more prevalent, disruption of the physiological circadian mechanism become a pathogenic factor of MetS. Therefore, MetS is now considered one of the "modern life chronobiological illness" (38).

The main occupational disruptor of the circadian rhythm are shifts. Working in shifts induces a misalignment of the physiological 
circadian rhythm and creates the conditions for shorter sleep duration and unhealthier habits. Nutritional intake during the night, when the hormonal and adipokine transcripts profile corresponds to the fasting state (e.g. low insulin, high glucagon) and when the tissular sensitivity is lower $(35,45)$, contributes to a raise of the glycemic level. In humans, the area above baseline of postprandial glucose excursion, is lowest at breakfast, reflecting a better glucose tolerance at breakfast than at lunch or dinner; this was also related to the higher postprandial levels of insulin after breakfast than after other meals of the day (46). Interestingly, hepatic insulin extraction was also lower at breakfast comparing to lunch and dinner.

How desynchronization of sleep affects metabolism was studied in healthy individuals. A delaying in sleep of 4 hours, for 3 consecutive days, reduced the rhytmic transcripts in human blood from $6 \%$ to $1 \%$, apart from an influence of the melatonin secretion. The transcripts affected were regulators of the epigenetic modifications, RNA polymerases, factors influencing the translation process, or core clock genes (36). Overall, the desynchronization affected, through this transcripts, a significant number of gene expressions of the organism. An imposed awakesleep cycles longer than $24 \mathrm{~h}$, led to higher levels of plasma glucose and triglycerides (47). After 3 days of $12 \mathrm{~h}$ shift protocol, mimicking a possible working schedule, the transcriptome analysis of the muscle biopsies showed significant differences of the PPAR pathway compared to the basal levels, upregulating the fatty acids pathways; reduced muscular sensitivity to insulin related to a significantly low glycogen synthesis and to impairement of the mithocondrial oxidative capacity. The plasmatic levels with elevated fatty acids and glycemia reflect the cellular modifications in metabolism (48).

Night shifts or early shifts are, by themselves, desynchronization factors. Shift nurses exhibited lower circadian variantions of peripheral skin temperature and cortisol variations (49). Melatonin secretion is influenced by the work schedule, the intensity of exposure to light and the wavelenght of the light wave during the shift working (50). The insulin sensitivity is different during the night both from delayed pancreatic secretion and from increased peripheral resistance. After 2 consecutive night shifts, the peak of insulin and C-peptide after meal ingestion was delayed, as was the nadir glucagon supression (51). Night shift might also interfere the inflammation mechanisms : high levels of high sensitivity protein $\mathrm{C}$ and leucocite blood count were found in shift working individuals, after adjustment for age, body mass index (BMI), waist circumference, alcohol consumption, smoking, exercise and sleep duration and insufficiency $(2,52)$. Together with the autonomic nervous system activity disregulation, the low grade, persistent inflammation increases the 24hour systolic blood pressure by $3.0 \mathrm{mmHg}$ and 24-hour diastolic blood pressure by $1.5 \mathrm{mmHg}$ (53).

Shorter sleep duration time, in both men and women, was, significantly, associated with higher BMI and waist circumference measures (54) and was defined as risk factor for MetS in in general population studies (55-57). Garaulet et al (38) have summarized the pathways of insulin resistance. The direct effect of insulin resistance is related to the increase in the conterregulatory insulin mechanisms (cortisol, growth hormone and sympathetic activity) and the indirect one is represented by the fat accumulation (obesity). Obesity is related to appetite sensation and the nutritional intake, and it is facilitated by the elevated levels of orexin and ghrelin and the lower leptin levels, combined with an increased time and opportunity break to eat. Impairement of glucose tolerance in healthy individuals, with temporary sleep restriction, was documeted several years ago (58) and confirmed by more recent studies among healthy people (59). The insulin sensitivity, assessed by intravenous glucose test, was reduced, on average, by $20 \%$. Peripheral resistance, estimated by the euglycemic hyperinsulinemic clamp, was reflected in $11 \%$ decreased dextrose infusion rate, in the final hours of the clamp procedure (59). In non diabetics, overweight/obese persons, the comparison between the insulin resistant to the non-resistant ones, revealed significant higher percentage of individuals with less than 7 hours of sleep per night in the insulin resistant group (60).

Studies exploring the interaction between 
sleep restriction and forced misalignment showed decreased sensitivity of insulin and elevated levels of the inflammatory biomarkers, independently of the sleep restriction (61). These results were confirmed in a cross sectional study on a hospital women personnel by an association between MetS and duration of night shift, with no sleep latency and sleep efficiency, as estimators for a poor quality of sleep (62). Even so, the importance of the recovery sleep should not be ignored among shift workers. Sleep efficiency seems to be less pronounced in shift, compared to non-shift individuals, in terms of restoring plasma insulin, triglyceride and non esterified fatty acids levels (63).

\section{Conclusions}

The experimental research, both in vitro and in vivo, provided consistent data and mechanistic explanations for the relation between the MetS and working in shifts. Different pathophysiological pathways of the lipid and carbohydrate metabolism lead to insulin resistance, diabetes and cardiovascular disease. In terms of prevention, in occupational medicine, the MetS and shift working should be approached from many angles. As night or rotating shifts cannot be avoided in many occupational settings, the recognition of MetS' risk and the identification of the early biomarkers of exposure to diabetes and cardiovascular diseases is crucial. The interest in chronobiology increases more and more. An important step forward would be the implementation of interventional programs to promote nutrition, physical activity and sleep hygiene in companies in which the risk is present.

\section{References:}

1. Beilby J. Definition of Metabolic Syndrome: Report of the National Heart, Lung, and Blood Institute/American Heart Association Conference on Scientific Issues Related to Definition. Circulation. 2006;109:433-438.

2. Buchvold HV, Pallesen S, Oyane NM, Bjorvatn B. Associations between night work and BMI, alcohol, smoking, caffeine and exercise--a cross-sectional study. BMC public health. 2015;15:1112.
3. Wang XS, Travis RC, Reeves G, Green J, Allen NE, Key TJ, Roddam AV, Beral V. Characteristics of the Million Women Study participants who have and have not worked at night. Scand J Work Environ Health. 2012;38:590-599.

4. Ramin C, Devore EE, Wang W, Pierre-Paul J, Wegrzyn LR, Schernhammer ES. Night shift work at specific age ranges and chronic disease risk factors. Occup Environ Med. 2015;72(2):100-107.

5. van Amelsvoort LGPM, Jansen NWH, Kant I. Smoking among shift workers: more than a confounding factor. Chronobiol Int. 2006;23(6):1105-1113.

6. van Drongelen A, Boot CRL, Merkus SL, Smid T, van der Beek AJ. The effects of shift work on body weight change - a systematic review of longitudinal studies. Scand J Work Environ Health. 2011;37(4): 263-275.

7. Kim M-J, Son K-H, Park H-Y, Choi D-J, Yoon C-H, Lee H-Y, Cho E-Y, Cho M-C. Association between shift work and obesity among female nurses: Korean Nurses' Survey. BMC Public Health. 2013;13:1204. doi:10.1186/1471-2458-13-1204.

8. Griep RH, Bastos LS, Fonseca Mde J, SilvaCosta A, Portela LF, Toivanen S, Rotenberg L. Years worked at night and body mass index among registered nurses from eighteen public hospitals in Rio de Janeiro, Brazil. BMC Health Serv Res. 2014;14:603. doi: 10.1186/s12913-014-0603-4.

9. Peplonska B, Bukowska A, Sobala W. Association of Rotating Night Shift Work with BMI and Abdominal Obesity among Nurses and Midwives. PLoS ONE. 2015;10(7):e0133761. doi:10.1371/journal. pone. 0133761 .

10. Sun M, Feng W, Wang F, Li P, Li Z, Li M, Tse G, Vlaanderen J, Vermeulen R, Tse LA. Metaanalysis on shift work and risks of specific obesity types. Obes Rev. 2018;19(1):28-40.

11. Gadallah M, Hakim SA, Mohsen A, Eldin WS. Association of rotating night shift with lipid profile among nurses in an Egyptian tertiary university hospital. East Mediter Health J. 2017;23(4):295-302.

12. Ghiasvand M, Heshmat R, Golpira R, Haghpanah V, Soleimani A, Shoushtarizadeh 
P, Tavangar SM, Larijani B. Shift working and risk of lipid disorders: A crosssectional study. Lipids Health Dis. 2006;5:9. doi:10.1186/1476-511X-5-9.

13. Karlsson B, Knutsson A, Lindahl B. Is there an association between shift work and having a metabolic syndrome? Results from a population based study of 27485 people. Occup Environ Med. 2001;58(11):747-752

14. Charles LE, Gu JK, Tinney-Zara CA, Fekedulegn D, Ma CC, Baughman P, Hartley TA, Andrew ME, Violanti JM, Burchfiel CM. Separate and Joint Associations of Shift Work and Sleep Quality with Lipids. Saf Health Work. 2016;7(2):111-119.

15. Dochi M, Sakata K, Oishi M, Tanaka K, Kobayashi E, Suwazono Y. Relationship between shift work and hypercholesterolemia in Japan. Scand J Work Environ Health. 2008;34(1):33-39.

16. Oyama I, Kubo T, Fujino Y, Kadowaki K, Kunimoto M, Shirane K, Tabata H, Sabanai K, Nakamura T, Matsuda S. Retrospective cohort study of the risk of impaired glucose tolerance among shift workers. Scand J Work Environ Health. 2012;38(4):337-342.

17. Karlsson B, Alfredsson L, Knutsson A, Andersson E, Torén K. Total mortality and cause-specific mortality of Swedish shift- and dayworkers in the pulp and paper industry in 1952-2001. Scand J Work Environ Health. 2005;31(1):30-35

18. Pan A, Schernhammer ES, Sun Q, Hu FB. Rotating Night Shift Work and Risk of Type 2 Diabetes: Two Prospective Cohort Studies in Women. PLoS Med. 2011; 8(12): e1001141. doi:10.1371/journal.pmed.1001141.

19. Manodpitipong A, Saetung S, Nimitphong $\mathrm{H}$, Siwasaranond $\mathrm{N}$, Wongphan T, Sornsiriwong C, Luckanajantachote P, Mangjit P, Keesukphan P, Crowley SJ, Hood MM, Reutrakul S. Night-shift work is associated with poorer glycaemic control in patients with type 2 diabetes. J Sleep Res. 2017;26(6): 764-772.

20. Thomas C, Power C. (2010). Shift work and risk factors for cardiovascular disease: a study at age 45 years in the 1958 British birth cohort. Eur J Epidemiol. 2010;25:305-314. inep?

21. de Gaudemaris R, Levant A, Ehlinger V,
Hérin F, Lepage B, Soulat JM, Sobaszek A, Kelly-Irving M, Lang T. Blood pressure and working conditions in hospital nurses and nursing assistants. The ORSOSA study. Arch Cardiovasc Dis. 2011;104(2):97-103.

22. Vetter C, Devore EE, Wegrzyn LR, Massa J, Speizer FE, Kawachi I, Rosner B, Stampfer MJ, Schernhammer ES. Association Between Rotating Night Shift Work and Risk of Coronary Heart Disease Among Women. JAMA. 2016; 315(16):1726-1734. PMC5102147.

23. Suwazono Y, Dochi M, Sakata K, Okubo Y, Oishi M, Tanaka K, Kobayashi E, Nogawa $\mathrm{K}$. Shift work is a risk factor for increased blood pressure in Japanese men: a 14year historical cohort study. Hypertension. 2008;52(3):581-586.

24. Silva-Costa A, Guimarães J, Chor D, de Jesus Mendes da Fonseca M, Bensenor I, Santos I, Barreto S, Griep RH. Time of exposure to night work and carotid atherosclerosis: a structural equation modeling approach using baseline data from ELSA-Brasil. Int Arch Occup Environ Health. 2018;91(5):591-600.

25. Yeom JH, Sim CS, Lee J, Yun SH, Park SJ, Yoo CI, Sung JH. Effect of shift work on hypertension: cross sectional study. Ann Occup Environ Med.2017; 29:11.

26. Manohar S, Thongprayoon C, Cheungpasitporn W, Mao MA, Herrmann SM. Associations of rotational shift work and night shift status with hypertension: a systematic review and meta-analysis. J Hypertens. 2017; 35(10):1929-1937.

27. Pietroiusti A, Neri A, Somma G, Coppeta L, Iavicoli I, Bergamaschi A, Magrini A. Incidence of metabolic syndrome among night-shift healthcare workers. Occup Environ Med. 2010;67(1):54-57.

28. Sawaengdee K, Tangcharoensathien $\mathrm{V}$, Theerawit T, Thungjaroenkul $\mathrm{P}$, Thinkhamrop W, Prathumkam P, Chaichaya $\mathrm{N}$, Thinkhamrop K, Tawarungruang C, Thinkhamro B. Thai nurse cohort study: cohort profiles and key findings. BMC Nurs. 2016; 15: 10.

29. Hundrup YA, Simonsen MK, Jørgensen T, Obel EB. Cohort Profile: The Danish nurse cohort. Int J Epidemiol. 2012;41(5):1241- 
1247.

30. Mazurenko O, Gupte G, Shan G. Analyzing U.S. nurse turnover: Are nurses leaving their jobs or the profession itself? J Hosp Admin. 2015;4(4):48-56.

31. Hulsegge G, Picavet HSJ, van der Beek AJ, Verschuren WMM, Twisk JW, Proper KI. Shift work, chronotype and the risk of cardiometabolic risk factors, Eur J Public Health. 2018; doi: 10.1093/eurpub/cky092.

32. Vetter C, Dashti HS, Lane JM, Anderson SG, Schernhammer ES, Rutter MK, Saxena R, Scheer FAJL. Night Shift Work, Genetic Risk, and Type 2 Diabetes in the UK Biobank. Diabetes Care. 2018;41(4):762-769.

33. Rotter M, Brandmaier S, Covic M, Burek K, Hertel J, Troll M, Bader E, Adam J, Prehn C, Rathkolb B, Hrabe de Angelis, M, Grabe HJ Daniel H, Kantermann T, Harth V, Illig T, Pallapies D, Behrens T, Brüning T, Adamski J, Lickert H, Rabstein S, Wang-Sattler R. Night Shift Work Affects Urine Metabolite Profiles of Nurses with Early Chronotype. Metabolites. 2018; 8(3):45.

34. Mohawk JA, Green CB, Takahashi JS. Central and peripheral circadian clocks in mammals. Ann Rev Neurosci. 2012;35:445462.

35. Carrasco-Benso MP, Rivero-Gutierrez B, Lopez-Minguez J, Anzola A, DiezNoguera A, Madrid JA, Lujan JA, MartínezAugustin O, Scheer FA, Garaulet M. Human adipose tissue expresses intrinsic circadian rhythm in insulin sensitivity. FASEB J. 2016;30(9):3117-3123.

36. Archer SN, Laing EE, Möller-Levet CS, van der Veen DR, Bucca G, Lazar AS, Santhi N, Slak A, Kabiljo R, von Schantz M, Smith CP, Dijk DJ. Circadian desynchrony and the human transcriptome. Proc Nat Acad Sci. 2014; 111(6):E682-E691.

37. Brown SA. Circadian Metabolism: From Mechanisms to Metabolomics and Medicine. Trends in Endocrinol \& Metab. 2016;27(6):415-452.

38. Garaulet M, Ordovás JM, Madrid JA. The chronobiology, etiology and pathophysiology of obesity. Int J Obes. 2010;34:1667-83.

39. Jacobi D, Liu S, Burkewitz K, Kory N, Knudsen NH, Alexander RK, Unluturk U,
Li X, Kong X, Hyde AL, Gangl MR, Mair $\mathrm{WB}$, Lee $\mathrm{CH}$. Hepatic Bmall regulates rhythmic mitochondrial dynamics and promotes metabolic fitness. Cell Metab. 2015;22(4):709-720.

40. McCarthy JJ, Andrews JL, McDearmon EL, Campbell KS, Barber BK, Miller BH, Walker JR, Hogenesch JB, Takahashi JS, Esser KA. Identification of the circadian transcriptome in adult mouse skeletal muscle. Physiol Genomics. 2007;31(1):86-95.

41. Lee J, Kim M-S, Li R, Liu VY, Fu L, Moore DD, Ma K, Yechoor VK. Loss of Bmall leads to uncoupling and impaired glucosestimulated insulin secretion in $\beta$-cells. Islets. 2011;3(6): 381-388.

42. Langin D. The role of uncoupling protein 2 in the development of type 2 diabetes. Drugs Today (Barc). 2003;39(4):287-295.

43. Dallmann R, Viola AU, Tarokh L, Cajochen C, Brown SA. The human circadian metabolome. Proc. Natl. Acad. Sci. USA. 2012;109(7):2625-2629.

44. Chua EC-P, Shui G, Lee IT-G, Lau P, Tan LC, Yeo SC, Lam BD, Bulchand S, Summers SA, Puvanendran K, Rozen SG, Wenk MR, Gooley JJ. Extensive diversity in circadian regulation of plasma lipids and evidence for different circadian metabolic phenotypes in humans. Proc Natl Acad Sci USA. 2013; 110(35):14468-1447.

45. Mattson MP, Allison DB, Fontana L, Harvie M, Longo VD, Malaisse WJ, Mosley M, Notterpek L, Ravussin E, Scheer FA, Seyfried TN, Varady KA, Panda S. Meal frequency and timing in health and disease. Proc Natl Acad Sci USA. 2014;111(47):16647-16653.

46. Saad A, Dalla Man C, Nandy DK, Levine JA, Bharucha AE, Rizza RA, Basu R, Carter RE, Cobelli C, Kudva YC, Basu A. Diurnal Pattern to Insulin Secretion and Insulin Action in Healthy Individuals. Diabetes. 2012;61(11):2691-2700. doi:10.2337/db111478.

47. Morgan L, Arendt J, Owens D, Folkard S, Hampton S, Deacon S, English J, Ribeiro D, Taylor K. Effects of the endogenous clock and sleep time on melatonin, insulin, glucose and lipid metabolism. J. Endocrinol. 1998; 157(3):443-451. 
48. Wefers J, van Moorsel D, Hansen J, Connell NJ, Havekes B, Hoeks J, van Marken Lichtenbelt WD, Duez H, Phielix E, Kalsbeek A, Boekschoten MV, Hooiveld GJ, Hesselink MKC, Kersten S, Staels B, Scheer FAJL, Schrauwen P. Circadian misalignment induces fatty acid metabolism gene profiles and compromises insulin sensitivity in human skeletal muscle. Proc Natl Acad Sci USA. 2018;115(30):7789-7794.

49. Bracci M, Ciarapica V, Copertaro A, Barbaresi M, Manzella N, Tomasetti M, Gaetani S, Monaco F, Amati M, Valentino M, Rapisarda V, Santarelli L. Peripheral Skin Temperature and Circadian Biological Clock in Shift Nurses after a Day off. Int J Molec Sci.2016;17(5):623.

50. Stevens RG, Zhu Y. Electric light, particularly at night, disrupts human circadian rhythmicity: is that a problem? Philos Trans R Soc B Biol Sci. 2015;370(1667) pii: 20140120.

51. Sharma A, Laurenti MC, Man CD, Varghese RT, Cobelli C, Rizza RA, Matveyenko A, Vella A. Glucose metabolism during rotational shift-work in health-care workers. Diabetologia. 2017;60(8):14831490.

52. Kim S-W, Jang E-C, Kwon S-C, Han W, Kang MS, Nam YH, Lee YJ. Night shift work and inflammatory markers in male workers aged 20-39 in a display manufacturing company. Ann Occup Environ Med. 2016;28:48. doi:10.1186/s40557-016-0135-y.

53. Morris CJ, Purvis TE, $\mathrm{Hu} \mathrm{K}$, Scheer FAJL. Circadian misalignment increases cardiovascular disease risk factors in humans. Proc Nat Acad Sci USA. 2016; 113(10):E1402-E1411.

54. Gildner TE, Liebert MA, Kowal P, Chatterji S, Josh Snodgrass J. Sleep Duration, Sleep Quality, and Obesity Risk Among Older Adults From Six Middle-Income Countries: Findings from the Study on global ageing and adult health (SAGE). Am J Hum Biol. 2014;26(6):803-812.

55. Song Q, Liu X, Zhou W, Wang X, Wu $S$. Changes in sleep duration and risk of metabolic syndrome: the Kailuan prospective study. Sci Rep. 2016;6:36861 doi: 10.1038/ srep36861

56. Vorona RD, Winn MP, Babineau TW, Eng BP, Feldman HR, Ware JC. Overweight and obese patients in a primary care population report less sleep than patients with a normal body mass index. Arch Intern Med. 2005;165(1): 25-30.

57. Gangwisch JE, Malaspina D, Boden-Albala B, Heymsfield SB. Inadequate sleep as a risk factor for obesity: analyses of the NHANES I. Sleep. 2005;28(10):1289-1296.

58. Spiegel K, Leproult R, Van Cauter E. Impact of sleep debt on metabolic and endocrine function. Lancet. 1999;354(9188):14351439.

59. Buxton OM, Pavlova M, Reid EW, Wang W, Simonson DC, Adler GK. Sleep Restriction for 1 Week Reduces Insulin Sensitivity in Healthy Men. Diabetes. 2010;59(9):21262133.

60. Liu A, Kushida CA, Reaven GM. Habitual Shortened Sleep and Insulin Resistance: an Independent Relationship in Obese Individuals. Metabolism. 2013;62(11):10.

61. Leproult R, Holmbäck U, Van Cauter E. Circadian Misalignment Augments Markers of Insulin Resistance and Inflammation, Independently of Sleep Loss. Diabetes. 2014;63(6):1860-1869.

62. Lajoie P, Aronson KJ, Day A, Tranmer J. A cross-sectional study of shift work, sleep quality and cardiometabolic risk in female hospital employees. BMJ Open. 2015;5:e007327.

63. Wehrens SMT, Christou S, Isherwood C, Middleton B, Gibbs MA, Archer SN, Skene DJ, Johnston JD. Meal Timing Regulates the Human Circadian System. Curr Biol. 2017;27(12):1768-1775. 